\title{
Use of an Ionic Liquid as a Co-solvent for Recyclable Pd/C-mediated $\mathrm{N}$-Debenzylation ${ }^{\dagger}$
}

\author{
Jin Kyu Choi, Byung Sun Jeon, Jong Hyun Cho, and B. Moon Kim* \\ Department of Chemistry, College of Natural Sciences, Seoul National University, Seoul 151-742, Korea \\ *E-mail:kimbm@snu.ac.kr \\ Received November 29, 2009, Accepted January 21, 2010
}

Key Words: Pd/C, $N$-Debenzylation, Co-solvent, Ionic liquid, Recycling

Benzyl group is a widely used protecting group for amino, hydroxyl and sulfurhydryl groups in peptide and carbohydrate chemistry. ${ }^{1}$ Its popularity as a protecting group owes to its chemical stability under various reaction conditions including strongly acidic and basic environments. However, this robust character of the benzyl group sometimes turns out to be a liability when it comes to its deprotection. For the deprotection of the $N$-benzyl group, a variety of methods have been reported including hydrogenation with $\mathrm{Pd} / \mathrm{C}$ at high or atmospheric pressure, ${ }^{2}$ catalytic transfer hydrogenation in acidic media ${ }^{3}$ or with ammonium formate, ${ }^{4}$ oxidation with molecular oxygen, ${ }^{5}$ use of Lewis acids, or employment of photosensitized single electron transfer reaction ${ }^{6}$ and use of other reagents. ${ }^{7}$ Except for the catalytic hydrogenation and transfer hydrogenation employing ammonium formate, ${ }^{2-4}$ most of the methods require rather harsh reaction conditions for satisfactory yields of the debenzylation. From our continued interest in peptidomimetic chemistry, we were in search of mild and possibly recyclable deprotection methods for various $N$-benzyl and $N, N$-dibenzyl protected amino groups. If the reagents or catalysts for the debenzylation can be recycled, the process would be amenable to large scale, practical applications. ${ }^{8}$

Recently, ionic liquids, made of organic cations and various anions, have emerged as powerful solvents or catalysts due to their peculiar physical and chemical properties such as high polarity, low melting point, non-volatile character, poor coordination, and immiscibility with other organic solvents. ${ }^{9}$ Recently various attempts have been made to use Pd nanoparticle catalysts in ionic liquid media. ${ }^{10,11}$ It has been reported that the ionic liquids can be utilized to accelerate and enhance selectivities in a number of organic reactions. After several attempts of rather capricious deprotection of various $N$-benzyl- and $N, N$-dibenzylamino groups using $\mathrm{Pd} / \mathrm{C}$ under atmospheric pressure of hydrogen, we have examined ionic liquids as a co-solvent for $N$-debenzylation, keeping in mind particularly a possibility of recycling through the immobilization of the catalyst in an ionic liquid. Herein, we wish to report on the mild and efficient debenzylation of various $N$-benzyl- and $N, N$-dibenzylamino derivatives using 1- $n$-butyl-3-methylimidazolium (bmim) salts as co-solvents and efficient recycling of $\mathrm{Pd} / \mathrm{C}$ catalyst.

First we screened widely used, commercially available ionic liquids (1a-e) to select a proper solvent system for the debenzylation (Figure 1). Taking $N$-benzylpiperidine (2) as a representa-

${ }^{\dagger}$ This paper is dedicated to Professor Sunggak Kim on the occasion of his honorable retirement. tive substrate, reactions were carried out employing $50 \mathrm{wt} \%$ of $\mathrm{Pd} / \mathrm{C}$ relative to starting material under 1 atm of $\mathrm{H}_{2}$ in a combination of methanol and an ionic liquid for $16 \mathrm{~h}$ at room temperature. Then the reaction mixture was treated with $(\mathrm{Boc})_{2} \mathrm{O}$ for $12 \mathrm{~h}$ at room temperature and the $N$-Boc protected product 3 was extracted with a mixture of EtOAc and $n$-hexane (1:1 $\mathrm{v} / \mathrm{v})$. The extracted organic layer was concentrated under reduced pressure and purified on a silica gel chromatographic column $($ EtOAc: $n$-hexane $=1: 8$ to $1: 4 \mathrm{v} / \mathrm{v})$. The results are shown in Table 1.

From Table 1, it became clear that yield of $N$-debenzylation was highly dependent upon the counter-anion of the ionic liquid. The reaction in methanol alone without the use of any ionic liquid provided a $77 \%$ yield of the desired product after protection with Boc group. Use of $\mathrm{MeOH}$ and [bmim] $\mathrm{Cl}$ (1a) mixture provided only $34 \%$ yield of 3 (entry 2 ). Some improvement (70\% yield) was observed with the use of [bmim]OTf (1b) (entry 3). However, use of [bmim] $\mathrm{SbF}_{6}(\mathbf{1 c})$ and $\left[\mathrm{bmim} \mathrm{PF}_{6}\right.$ (1d) improved the yield noticeably to $82 \%$ and $93 \%$, respectively (entries 4 and 5) and the best result was obtained using [bmim] $\mathrm{BF}_{4}(\mathbf{1 e})$ as co-solvent giving $96 \%$ yield of the desired product (entry 6).

Using the proper solvent system identified in Table 1, we

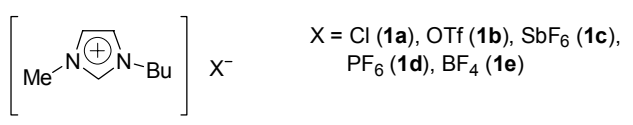

Figure 1. Various ionic liquids.

Table 1. Screening of ionic liquids for $N$-debenzylation

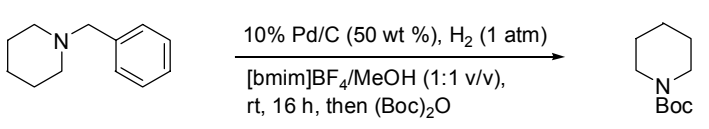

2 $\mathrm{rt}, 16 \mathrm{~h}$, then $(\mathrm{Boc})_{2} \mathrm{O}$

\begin{tabular}{ccc}
\hline entry & ionic liquids used with methanol $(1: 1, \mathrm{v} / \mathrm{v})$ & yield $(\%)^{a}$ \\
\hline 1 & MeOH only & $77^{b}$ \\
2 & 1a & 34 \\
3 & 1b & 70 \\
4 & 1c & 82 \\
5 & 1d & 93 \\
6 & 1e & 96 \\
\hline
\end{tabular}

$\overline{{ }^{a} \text { Yields after purification on silica gel column. }{ }^{b} \text { About } 10 \% \text { starting material }}$ remained. 
Table 2. Screening the amount of the catalyst

\begin{tabular}{ccc}
\hline entry & wt $\%$ of $10 \% \mathrm{Pd} / \mathrm{C}$ & ${\text { yield }(\%)^{a}}^{a}$ \\
\hline 1 & 5 & 6 \\
2 & 10 & 19 \\
3 & 20 & 33 \\
4 & 50 & 96 \\
\hline
\end{tabular}

${ }^{\bar{a}} \overline{\text { Yields of Boc-protected amines after purification on silica gel column. }}$

Table 3. Search for the best organic co-solvent system in combination with $[\mathrm{bmim}] \mathrm{BF}_{4}$

\begin{tabular}{clcc}
\hline entry & solvent system $(\mathrm{v} / \mathrm{v})$ & time $(\mathrm{h})$ & ${\text { yield }(\%)^{a}}^{a}$ \\
\hline 1 & 1e $:$ THF $=1: 1$ & 16 & 76 \\
2 & 1e $:$ EtOAc $=1: 1$ & 16 & 86 \\
3 & 1e $:$ DCM $=1: 1$ & 16 & 84 \\
4 & $\mathbf{1 e}: \mathrm{MeOH}=1: 1$ & 16 & 96 \\
5 & $\mathbf{1 e}: \mathrm{MeOH}=1: 10$ & 16 & 62 \\
6 & $\mathbf{1 e}: \mathrm{MeOH}=1: 5$ & 16 & 59 \\
7 & $\mathbf{1 e}: \mathrm{MeOH}=5: 1$ & 16 & 25
\end{tabular}

${ }^{a}$ Isolated yields after purification of Boc-protected amines on silica gel column.

Table 4. Result on the $N$-debenzylation using $50 \mathrm{wt} \% \mathrm{Pd} / \mathrm{C}$ in $1: 1$ methanol/[bmim $] \mathrm{BF}_{4}$ followed by Boc-protection

entry substrate time (h) yield (\%)

${ }^{a}$ Yields after purification on silica gel column.

then investigated the influence on the yield of the amount of activated $\mathrm{Pd} / \mathrm{C}$ relative to that of the starting material using otherwise the same reaction conditions. As outlined in Table 2, use of less than $50 \mathrm{wt} \%$ of $\mathrm{Pd} / \mathrm{C}$ proved to be not effective in

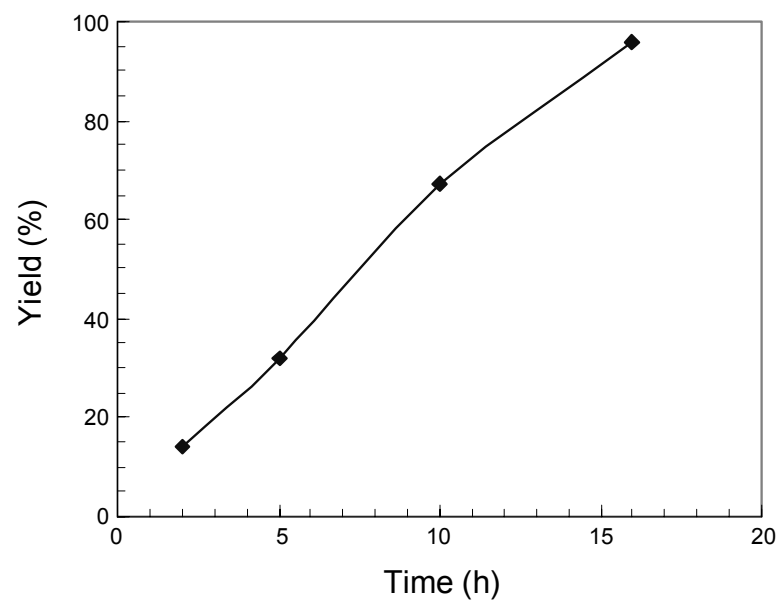

Figure 2. Yields of $\mathbf{3}$ at given reaction time.

the deprotection under given time period $(16 \mathrm{~h})$ at room temperature. In fact the yields were almost directly proportional to the amount of the catalyst system employed and use of 50 wt $\%$ of the catalyst was necessary to ensure the best result (96\% yield, entry 4 ).

We then examined reaction time required to complete the deprotection in [bmim] $\mathrm{BF}_{4} / \mathrm{MeOH}(1: 1 \mathrm{v} / \mathrm{v})$ using $50 \mathrm{wt} \%$ of $\mathrm{Pd} / \mathrm{C}$, and the results are outlined in Figure 2. The production of the deprotected amine was almost linearly proportional to the reaction time and at least $16 \mathrm{~h}$ was required to furnish the best result.

Examination of various organic co-solvents and their ratios in combination with 1e was also carried out under otherwise identical reaction conditions. The less polar solvents examined in Table 3, i.e. THF, ethyl acetate and dichloromethane, turned out to be somewhat inferior to methanol (entries 1-3). The ratio of methanol to the ionic liquid was also found to be critical; a 1:1 mixture of methanol and [bmim] $\mathrm{BF}_{4}$ was essential in ensuring the best yield of the deprotection (entry 4). Reactions in solvent systems employing $9 \%$ and $17 \%$ of the ionic liquid relative to methanol proceeded slowly (entries 5 and 6 , respectively). Use of a large excess of ionic liquid did not provide satisfactory result either, presumably due to low solubility of the substrate in the solvent system (entry 7).

With the efficient $N$-debenzylation method using the ionic liquid in hand, we carried out debenzylation of various monoand dibenzyl-protected amino derivatives as shown in Table 4.

Most of the $N$-benzyl derivatives of secondary amines and $\mathrm{N}, \mathrm{N}$-dibenzyl derivative of primary amines were successfully cleaved in the presence of $[\mathrm{bmim}] \mathrm{BF}_{4} / \mathrm{MeOH}(1: 1 \mathrm{v} / \mathrm{v})$ under $1 \mathrm{~atm}$ of $\mathrm{H}_{2}$ atmosphere at room temperature in $12 \sim 24 \mathrm{~h}$, providing more than $90 \%$ yields of the desired product after Bocprotection (entries 1-6). It is noteworthy that even $N, N$-dibenzyl derivative of sterically hindered L-phenylalanine methyl ester was cleanly converted to the corresponding Boc-protected amine in an excellent (96\%) yield under atmospheric pressure of hydrogen (entry 6).

We then investigated recycling capability of the ionic liquid for debenzylation. For the recycling experiment, we discovered that dichloromethane proved to be a better co-solvent than 
Table 5. Recycling investigation

\begin{tabular}{|c|c|c|c|c|c|c|c|c|c|c|c|}
\hline & & & & & $\frac{10 \% \mathrm{Pd} / \mathrm{C}}{\left[\begin{array}{r}\mathrm{bmim}] \mathrm{B} \\
\mathrm{rt}, 16\end{array}\right.}$ & $\begin{array}{l}\mathrm{H}_{2}( \\
1: 1 \mathrm{v/} \\
\mathrm{Boc})_{2}\end{array}$ & & 11 & & & \\
\hline cycle & 1 & 2 & 3 & 4 & 5 & 6 & 7 & 8 & 9 & 10 & $11^{b}$ \\
\hline yield $(\%)^{a}$ & 92 & 94 & 79 & 74 & 82 & 81 & 84 & 65 & 29 & 2 & 93 \\
\hline
\end{tabular}

${ }^{\bar{a}}$ Yields after purification on silica gel column. ${ }^{b}$ After 10 th recycling, fresh $\mathrm{Pd} / \mathrm{C}(50 \mathrm{wt} \%)$ was added.

$\mathrm{MeOH}$ since it gave better extraction profile. Therefore, the co-solvent was switched to dichloromethane to minimize the leaching out of palladium. After extraction with EtOAc/ $n$-hexane $(1: 1 \mathrm{v} / \mathrm{v})$ to separate the products from the reaction mixture, the residual black ionic liquid containing the $\mathrm{Pd} / \mathrm{C}$ suspension was directly reused for the next debenzylation. The reaction was recycled without addition of further $\mathrm{Pd} / \mathrm{C}$ and ionic liquid and the results are shown in Table 5. A slight drop in the yield after the 3rd recycling was observed, however, uniformly good yields were obtained from the 3 rd to the 7 th recycling. At the 8 th recycling experiment, the yield dropped considerably and at the 9 th, precipitously. This is presumably due to the leaching out of the palladium metal from the $\mathrm{Pd} / \mathrm{C}$ complex. ${ }^{12}$ Most of the starting material was recovered unchanged at the 10th recycling experiment. After 10th recycling experiment, a fresh batch of $10 \% \mathrm{Pd} / \mathrm{C}$ was added to the reaction mixture. In that case, a satisfactory yield (93\%) was obtained, indicating that the integrity of the ionic liquid after 10th recycling experiment was still intact.

In summary, an efficient deprotection method for $N$-benzylamine derivatives has been developed employing [bmim] $\mathrm{BF}_{4}$ as co-solvent under mild and non-acidic catalytic hydrogenation conditions. The best result was obtained for $N$-benzylpiperidine using $50 \mathrm{wt} \%$ of $\mathrm{Pd} / \mathrm{C}$ in $[\mathrm{bmim}] \mathrm{BF}_{4} / \mathrm{MeOH}(1: 1 \mathrm{v} / \mathrm{v})$ at $1 \mathrm{~atm}$ of $\mathrm{H}_{2}$ and room temperature. Using this protocol, $N$-benzyl group was successfully removed from various $N$-benzylamino derivatives in high yields. In recycling experiments, a slight, gradual decrease in yield was observed until a precipitous drop at the 8th recycle. The critical role of ionic liquid for this mild debenzylation and how to conserve the activity of $\mathrm{Pd}$ in ionic liquid are under investigation.

\section{Experimental Section}

General procedure for $\boldsymbol{N}$-debenzylation. To a stirred mixture solution of methanol $(1 \mathrm{~mL})$ and ionic liquid $(1 \mathrm{~mL})$ were added $N$-benzyl derivative (100 mg) and $10 \mathrm{wt} \% \mathrm{Pd} / \mathrm{C}(50 \mathrm{mg})$. Resulting suspension was vigorously stirred for $16 \mathrm{~h}$ at room temperature under atmospheric pressure of $\mathrm{H}_{2}$. Then $\mathrm{Boc}_{2} \mathrm{O}$ (1.2 equiv) was added and the mixture stirred for $12 \mathrm{~h}$. Methanol was evaporated under reduced pressure and the residue was extracted with a mixture of $n$-Hexane, EtOAc and $\mathrm{Et}_{2} \mathrm{O}$ ( 5 times each of 1.0, 1.0, and $2.0 \mathrm{~mL}$ 's, respectively). Combined organic phase was concentrated under reduced pressure. The crude product was purified through column chromatography on silica gel to afford the desired product.

For the repetition experiment, the ionic liquid phase after extraction with a mixture of organic solvents was reused for the next reaction.

Acknowledgments. This work was supported by the Korea Science and Engineering Foundation (KOSEF) grant funded by the Korea government (MEST) (No. R01-2008-000-20332-0).

\section{References}

1. (a) Greene, T. W.; Wuts, P. G. M. Protective Groups in Organic Synthesis; Wiley: New York, 1991. (b) Kocienski, P. J. Protecting Groups; Georg Thieme Stuttgart: New York, 1994.

2. For selected examples, see: (a) Bernotas, R. C.; Cube, R. V. Synth. Commun. 1990, 20, 1209-1212. (b) Cheng, C.; Sun, J.; Xing, L.; Xu, J.; Wang, X.; Hu, Y. J. Org. Chem. 2009, 74, 5671-5674. (c) David, A.; Vannice, M. A. J. Catal. 2006, 237, 349-358. (d) Gonzlez-Sabn, J.; Gotor, V.; Rebolledo, F. J. Org. Chem. 2007, 72, 1309-1314. (e) Kuehne, M. E.; Cowen, S. D.; Xu, F.; Borman, L. J. Org. Chem. 2001, 66, 5303-5316. (f) Asahina, Y.; Takei, M.; Kimura, T.; Fukuda, Y. J. Med. Chem. 2008, 51, 3238-3249.

3. For selected examples, see: (a) Means, G. E.; ElAmin, B.; Anantharamaiah, G. M.; Royer, G. P. J. Org. Chem. 1979, 44, 3442-3444. (b) Periasamy, M.; Kanth, J. V. B.; Reddy, C. K. Synth. Commun. 1994, 94, 313-319.

4. (a) Ram, S.; Spicer, L. D. Tetrahedron Lett. 1987, 28, 515-516. (b) Arefalk, A.; Larhed, M.; Hallberg, A. J. Org. Chem. 2005, 70, 938-942.

5. Deaton-Rewolinski, M. V.; Kelleman, A.; Haddach, A. A. Tetrahedron Lett. 2002, 43, 399-402.

6. (a) Banerji, A.; Talukdar, S.; Nayak, S. K. J. Org. Chem. 1998, 63, 4925-4929. (b) Pandey, G.; Rani, K. S. Tetrahedron Lett. 1988, $29,4157-4158$

7. (a) Grayson, E. J.; Davis, B. G. Org. Lett. 2005, 7, 2361-2364. (b) Chern, C.-Y.; Huang, Y.-P.; Kan, W. M. Tetrahedron Lett. 2003, 44, 1039-1041.

8. (a) Jansson, A. M.; Grøtli, M.; Halkes, K. M.; Meldal, M. Org. Lett. 2002, 4, 27-30. (b) Mukhopadhyay, S.; Ratner, S.; Spernat, A.; Qafisheh, N.; Sasson, Y. Org. Process Res. Dev. 2002, 6, 297300. (c) Yu, J. Q.; Wu, H. C.; Ramarao, C.; Spencer, J. B.; Ley, S. V. Chem Commun. 2003, 678-679.

9. For a review, see: (a) Welton, T. Chem. Rev. 1999, 99, 2071-2083. (b) Wasserscheid, P.; Keim, W. Angew. Chem. Int. Ed. 2000, 39, 3772-3789. (c) Tzschucke, C. C.; Markert, C.; Bannwarth, W.; Roller, S.; Hebel, A.; Hagg, R. Angew. Chem. Int. Ed. 2002, 41, 3964-3940. (d) Dyson, P. J. Appl. Organometal. Chem. 2002, 16, 495-500. (e) Dupont, J.; Souza, R. F.; Suarez, A. Z. Chem. Rev. 2002, 102, 3367-3692. (f) Oliver-Bourbigou, H.; Magna, L. J. Molecular Catalysis A: Chemical 2002, 182-183, 419-437. (g) Kou, Y.; Zhao, D.; Wu, M.; Min, E. Catalysis Today 2002, 74, 157-189. (h) Welton, T. Coord. Chem. Rev. 2004, 248, 2459-2477. (i) Parvulescu, V. I.; Hardacre, C. Chem. Rev. 2007, 107, 26152665. (j) Plechkova, N. V.; Seddon, K. R. Chem. Soc. Rev. 2008, 37, 123-150. (k) Weingärtner, H. Angew. Chem. Int. Ed. 2008, 47, 654-670. 
10. For a review, see: (a) Gu, Y.; Li, G. Adv. Synth. Catal. 2009, 351, 817-847. (b) Durand, J.; Teuma, E.; Gómez, M. Eur. J. Inorg. Chem. 2008, 3577-3586.

11. (a) Calo, V.; Nacci, A.; Monopoli, A. Eur. J. Org. Chem. 2006, 3791-3802. (b) Polshettiwar, V. Res. J. Chem. Environ. 2006, 10, 91-92.

12. It has been well documented in the literature that the heterogeneous metal catalysts such as $\mathrm{Pd} / \mathrm{C}$ work through a homogeneous catalyst system through a desorption/resorption mechanism. See, for example: (a) Biffs, A.; Zecca, M.; Basato, M. J. Mol. Catal. A 2001, 173, 249. (b) Roland, G.; Heidenreich, R. G.; Krauter, J. G. E.; Pietsch, J.; Köhler, K. J. Mol. Catal. A 2002, 182-183, 499-509. (c) Phan, N. T. S.; van der Sluys, M.; Jones, Ch. W. Adv. Synth. Catal. 2006, 348, 609. (d) Polshettiwar, V.; Molnar, A. Tetrahedron 2007, 63, 6949. (e) Zhao, F.; Bhanage, B. M.; Shirai, M.; Arai, M. Chem. Eur. J. 2000, 6, 843-848. 